\title{
Correction of Metabolic Alkalosis by the Kidney after Isometric Expansion of Extracellular Fluid
}

\author{
Jordan J. CoHEN with the technical assistance of JoHN H. Ellis \\ From the Division of Biological and Medical Sciences, Brown University, and \\ the Renal Division, Rhode Island Hospital, Providence, Rhode Island 02903
}

A в S T R A C T Metabolic alkalosis was induced in dogs by administering ethacrynic acid and sustained by feeding a chloride-deficient diet. At the height of the alkalosis extracellular fluid was expanded "isometrically," i.e., with an infusion that duplicated plasma sodium, chloride, and bicarbonate concentrations. Correction of metabolic alkalosis promptly followed such expansion and was attributed to the selective retention by the kidneys of chloride from the administered solution. Since plasma chloride concentration was not increased as an immediate consequence of the infusion, it is concluded that the change in renal tubular function that led to the selective retention of chloride must have been mediated by factors independent of filtrate chloride concentration.

A decrease in circulating mineralocorticoid level, as a consequence of volume expansion, does not seem to account for this change in tubular function since identical studies in dogs receiving excessive amounts of 11-deoxycorticosterone acetate during the day of infusion yielded similar findings. Moreover, no other consequence of volume expansion appears to be sufficient to cause this change in tubular function in the absence of metabolic alkalosis; when the alkalosis was corrected with hydrochloric acid before infusion, isometric expansion of extracellular volume did not induce selective chloride retention.

We suggest that isometric expansion during metabolic alkalosis causes a decrease in proximal sodium reabsorption that relinquishes filtrate to a more distal site in the nephron and that this site

Received for publication 9 October 1967 and in revised form 4 January 1968. may retain chloride preferentially when hypochloremia or chloride deficiency is present.

\section{INTRODUCTION}

Correction of metabolic alkalosis requires that plasma bicarbonate concentration and renal bicarbonate threshold be reduced to normal levels. Although recent studies in a variety of clinical and experimental situations have demonstrated clearly that such correction is critically dependent on the provision of adequate chloride (1-8), the precise mechanism whereby the provision of chloride permits restoration of normal acid-base equilibrium has not been elucidated.

It has been suggested that, before the administration of chloride, the low plasma concentration of this anion may be directly responsible for perpetuating the alkalosis. Since chloride is unique among physiologically prevalent anions in being readily reabsorbable by the kidney, it has been reasoned that sustained hypochloremia limits the availability of reabsorbable anion in the glomerular filtrate (6). Conservation of sodium filtered with inadequate reabsorbable anion would enhance the transtubular potential difference and accelerate sodium-cation exchange. To the extent that this sequence of events accelerates the rate of sodiumhydrogen exchange, a high rate of bicarbonate reabsorption by the kidney and an elevated plasma bicarbonate concentration would be maintained.

It is theoretically possible, therefore, that an increase in plasma chloride concentration towards normal might be a necessary first step in the process of correcting metabolic alkalosis. If the 
acceleration of renal sodium-hydrogen exchange that maintains metabolic alkalosis is the direct consequence of a low filtrate chloride concentration, the deceleration of sodium-hydrogen exchange that permits a fall in plasma bicarbonate concentration might require some previous increase in filtrate chloride concentration.

The present study explores this possibility in dogs rendered alkalotic by the administration of ethacrynic acid and a chloride-deficient diet. In order to provide adequate chloride without directly increasing glomerular filtrate chloride concentration, we expanded extracellular fluid volume isometrically, i.e., with a solution comparable in composition to plasma with respect to major electrolytes. Despite this restriction, the kidneys were able to retain administered chloride and reject excess bicarbonate selectively with prompt correction of the alkalosis.

It is concluded that the provision of chloride may alter over-all tubular function during the correction of metabolic alkalosis by mechanisms independent of filtrate chloride concentration. The associated expansion of extracellular fluid volume may be involved in mediating this effect of administered chloride.

\section{METHODS}

19 studies, including 11 with detailed balance observations, were carried out on 16 female mongrel dogs ranging in weight from 12 to $22 \mathrm{~kg}$. The animals were fed a synthetic diet consisting, by weight, of 10 parts dextrin, 10 parts casein, 6 parts hydrogenated vegetable oils (Crisco), 5.5 parts dextrose, USP, 1.2 parts purified agar, and 40 parts distilled water. Multivitamins (ABDEC Drops) and iron (Fer-in-sol) were added in liberal amounts. When properly prepared and refrigerated this mixture forms an easily handled, solid diet containing, by analysis, no more than $1 \mathrm{mEq}$ of sodium, $0.1 \mathrm{mEq}$ of potassium, and $0.5 \mathrm{mEq}$ of chloride per $100 \mathrm{~g}$. A daily allowance of this diet, $30 \mathrm{~g} / \mathrm{kg}$, was homogenized with $500-1000 \mathrm{ml}$ of hot distilled water shortly before feeding the dogs. Additional water was offered ad lib. The diet was supplemented with $3 \mathrm{mEq}$ of sodium per $\mathrm{kg}$ and $2 \mathrm{mEq}$ of potassium per $\mathrm{kg}$ per day, both as neutral phosphate (4 parts $\mathrm{HPO}_{4}=1$ part $\left.\mathrm{H}_{2} \mathrm{PO}_{4}^{-}\right)$. Most animals ate their total daily allowance throughout the study; some required tube feeding after the induction of metabolic alkalosis (see below). Fasting blood samples were obtained by percutaneous femoral artery puncture at $24-72-\mathrm{hr}$ intervals throughout the course of the study.

Experimental design. The chloride-deficient diet was fed for 3-5 days before beginning each study. Ensuing control periods were of 4-7 day's duration for the 11 studies involving detailed balance observations and of 2-3 day's duration for the remaining 8 studies.

Immediately after the control period, metabolic alkalosis was induced in all animals by the intravenous administration of ethacrynic acid, ${ }^{1} 1 \mathrm{mg} / \mathrm{kg}$ of body weight per day, for 4 or 5 consecutive days. The injections were given at least $3 \mathrm{hr}$ after the daily diet had been consumed and did not induce vomiting.

A few days after the last dose of ethacrynic acid, at the height of the metabolic alkalosis, one of four experimental protocols was introduced. In each instance the experimental protocol involved a $24-\mathrm{hr}$ period initiated by the rapid infusion of an individually tailored solution formulated as described below. The infusion day constituted the only experimental period except in protocol IV where an additional brief period preceded the infusion day.

Protocol I, standard infusion (eight animals, six balance studies). The objective of this protocol was to administer ample chloride to these chloride-depleted, alkalotic animals without altering the plasma concentration of major electrolytes. Accordingly, plasma sodium, chloride, and bicarbonate concentrations, determined in each study on the morning of the proposed infusion, were used to prepare the infusate. The concentration of undetermined anions, defined as sodium concentration minus the sum of chloride and bicarbonate concentrations, was accounted for by the addition of neutral phosphate to the infusion solution. The solution contained no potassium.

Animals were anesthetized with intravenous pentobarbital sodium and indwelling catheters were placed in a brachial vein, femoral artery, and the urinary bladder. After a preinfusion control period of 1-2 hr duration, "isometric" expansion was accomplished by administering the infusion solution at a rate of $50 \mathrm{ml} / \mathrm{kg}$ per hr for $3 \mathrm{hr}$ with a constant infusion pump. This rate of infusion was chosen in order to present each animal with approximately $50 \%$ more chloride during the $3 \mathrm{hr}$ infusion period than had been lost during the ethacrynic acid period (see Results).

Frequent arterial blood samples and consecutive urine periods were obtained before, during, and for $3 \mathrm{hr}$ after the infusion. Thereafter, the animals were returned to metabolic cages and offered $500 \mathrm{ml}$ of water in a pan. Urine voided during the night drained into collection bottles (see below). On the following morning, $24 \mathrm{hr}$ after beginning the infusion, a final arterial blood sample was obtained and the bladder was emptied by catheterization. No food was given during the $24 \mathrm{hr}$ infusion-day period.

Protocol II, low chloride infusion (three animals). The objective of this protocol was to administer an amount of chloride similar to that provided in protocol I but at a concentration substantially lower than that of the coexisting plasma. Accordingly, whereas the sodium and neutral phosphate concentrations of the infusion solution were determined as in protocol $\mathrm{I}$, the concentration of

${ }^{1}$ Merck Sharp and Dohme Research Laboratories, West Point, $\mathrm{Pa}$. 
chloride in the infusion solution was reduced to a value equal to one-half the concentration of chloride in the plasma. Additional bicarbonate made up the remaining anion equivalents producing a concentration of bicarbonate in the infusion solution that greatly exceeded the concentration of bicarbonate in the plasma. This solution was administered at a rate of $50 \mathrm{ml} / \mathrm{kg}$ per $\mathrm{hr}$ for 6 rather than $3 \mathrm{hr}$ in order to provide a total amount of chloride comparable to that provided in protocol I, In all other respects protocol II followed the pattern set by protocol I.

Protocol III, standard infusion plus 11-deoxycorticosterone acetate (DOCA) (three animals). This protocol was identical with protocol I with the exception that 10 $\mathrm{mg}$ of DOCA in oil was administered intramuscularly 12 and $2 \mathrm{hr}$ preceding the infusion and an additional 2.5 $\mathrm{mg}$ of an aqueous suspension of DOCA was added to each liter of infusate.

Protocol IV, standard infusion after correction of metabolic alkalosis with hydrochloric acid (five animals, five balance studies). The objective of this protocol was to repair the plasma chloride and bicarbonate concentrations before infusion without repairing the sodium or potassium deficits. Accordingly, after the induction of metabolic alkalosis, an additional experimental period of 2-6 days preceded the infusion day. Supplemental sodium and potassium were eliminated from the diet throughout this period and hydrochloric acid was added to the diet (tube fed in all cases) on each of the initial 2 days of this period; the amount of hydrochloric acid added (25-100 mmoles/day) was adjusted for each dog in an effort to reduce plasma bicarbonate concentration to as close to control levels as possible.

An infusion day protocol identical with protocol I was then employed; as in the preceding studies, the composition of the infusion solution approximated the plasma sodium, chloride, and bicarbonate values obtained immediately before infusion. In contrast to the previous studies, however, these animals were not hypochloremic immediately before infusion and, hence, received a relatively larger amount of chloride from the infusion (see Results).

Balance technique. Animals were kept in metabolic cages throughout the control and alkalosis periods. Urine was voided over siliconized metal surfaces into bottles containing mineral oil and thymol chloroform. When tested with water, this system yielded greater than $98 \%$ recovery. Collection bottles were changed at 9 a.m. daily. Feces were pooled during both the control and alkalosis periods; collections were started and terminated $24 \mathrm{hr}$ later than the corresponding periods. Daily balances were calculated as the difference between the net intake and the combined outputs in urine, stool, and blood samples. The change in net external balance during the alkalosis period was calculated as the difference between the average daily balance during the control period and the daily balance during the alkalosis period. The external balance on the day of infusion was calculated as the difference between the amount infused and the combined outputs in urine and blood samples.
Quantitative urine collections were also obtained during the six nonbalance studies comprising protocols II and III in order to permit estimates of the chloride deficits induced by the administration of ethacrynic acid to these animals.

Analytical procedures. Blood and urine $\mathrm{pH}$ were determined anaerobically at $38^{\circ} \mathrm{C}$ with Metrohm Ltd., Herisan, Switzerland water-jacketed, capillary glass electrode and Radiometer, expanded-scale $\mathrm{pH}$ meter. Total carbon dioxide content of plasma and urine were determined by the manometric method of Van Slyke and Neill. Carbon dioxide tension and bicarbonate concentration were calculated from the Henderson-Hasselbalch equation using a $\mathrm{pK}^{\prime}$ of 6.10 and solubility coefficients of 0.0301 and 0.0309 for plasma and urine, respectively. Sodium and potassium concentration were determined by flame photometry with lithium internal standard. Chloride concentration was determined by the method of Cotlove and Nishi (9). Electrolyte contents of feces and diet were determined on nitric acid extracts. The Technicon AutoAnalyzer was used to measure blood and urine phosphate by the method of Fiske and Subbarow (10) and urinary ammonia by the method of Logsdon (11). Titratable acidity was calculated from urinary phosphate excretion with a $\mathrm{pK}$ of 6.8. Net acid excretion was estimated as the sum of urinary ammonia and titratable acidity minus urinary bicarbonate. Changes in extracellular fluid volume were estimated from "chloride space" calculations assuming an initial value of $20 \%$ of body weight.

\section{RESULTS}

\section{Protocol I}

Pertinent plasma values and balance observations are depicted in Fig. 1 for one representative study $(\operatorname{dog} 7)$.

\section{Plasma Values}

Table I contains sodium, chloride, bicarbonate, and undetermined anion concentrations for all eight animals undergoing the standard protocol. Control values represent the average of the two to five observations obtained before the administration of ethacrynic acid. "Alkalosis" values represent the average of the three to four observations obtained in the 1 st or $2 \mathrm{nd} \mathrm{hr}$ immediately before the infusion and correspond to the height of the metabolic alkalosis. The "after infusion day" values were obtained $24 \mathrm{hr}$ after beginning the infusion. The solid line in Fig. 2 depicts the average sodium, chloride, and bicarbonate concentrations at each of these times for all animals in this protocol.

Sodium concentration fell from an average control value of $151-144 \mathrm{mEq} /$ liter $(P<0.01)$ 


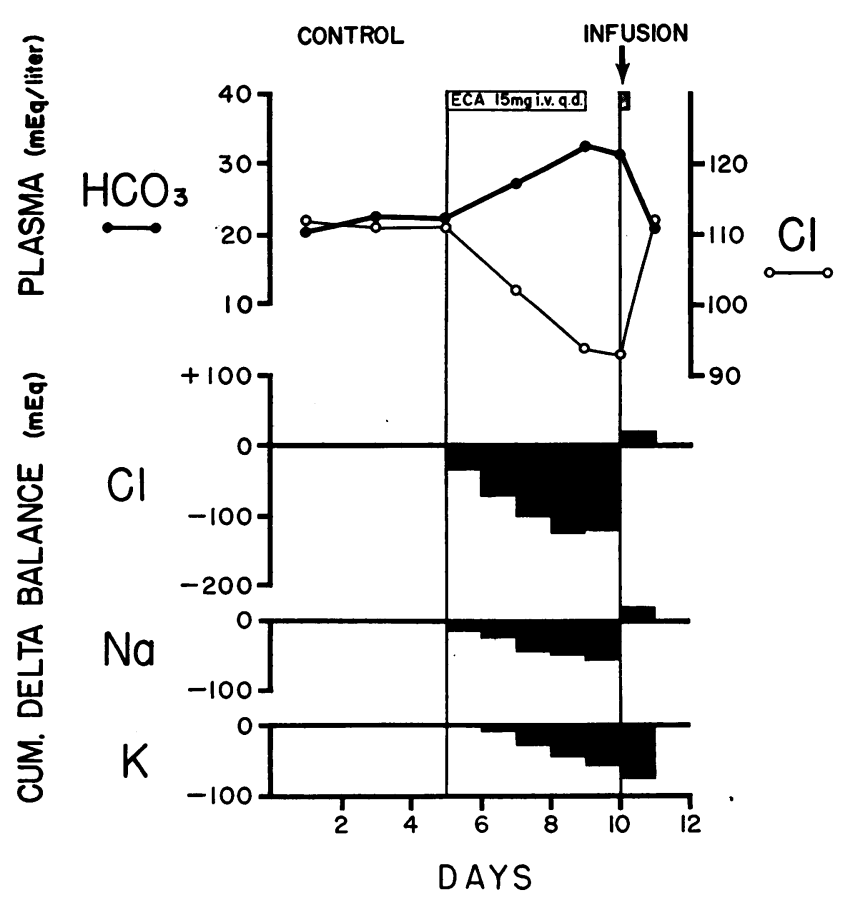

FIGURE 1 Plasma concentrations of bicarbonate and chloride and cumulative (CUM) delta balances of chloride, sodium, and potassium during the time course of one representative study from protocol I. (Dog 7). Note that the metabolic alkalosis and sodium and chloride deficits were repaired by the day after "isometric" expansion with the individually tailored infusion. ECA, ethacrynic acid. in response to ethacrynic acid and returned to $150 \mathrm{mEq} /$ liter after the infusion. Chloride concentration followed a similar but much more striking pattern, falling from an average control value of 109 to $86 \mathrm{mEq} /$ liter $(P<0.01)$ and returning to $106 \mathrm{mEq} /$ liter by the morning after infusion. Bicarbonate concentration mirrored the change in chloride concentration; the control value rose from an average of 21.8 to $31.4 \mathrm{mEq} /$ liter after ethacrynic acid $(P<0.01)$ and fell to an average of $24.1 \mathrm{mEq} /$ liter by the morning after the infusion. Undetermined anion concentration averaged $20 \mathrm{mEq} /$ liter during the control period, rose to $28 \mathrm{mEq} /$ liter before the infusion $(P<$ 0.01 ), and fell to $20 \mathrm{mEq} /$ liter after the infusion. There were no statistically significant differences between the control and "after infusion day" concentrations of sodium, chloride, bicarbonate, or undetermined anions.

In six of these eight animals blood samples were also obtained $48 \mathrm{hr}$ after beginning the infusion. In these animals average chloride concentration had increased by an additional $4 \mathrm{mEq} /$ liter and average bicarbonate concentration had decreased by an additional $1.9 \mathrm{mEq} /$ liter beyond their respective values $24 \mathrm{hr}$ after infusion.

Mean potassium concentration was $3.4 \mathrm{mEq} /$ liter during the control period, fell to $2.0 \mathrm{mEq} /$ liter before the infusion $(P<0.01)$, and rose to $2.3 \mathrm{mEq} /$ liter after the potassium-free infusion $(P<0.01)$.

Arterial hydrogen ion concentration averaged $36.9 \mathrm{nEq} /$ liter $(\mathrm{pH} 7.43)$ during the control period, fell to $31.0 \mathrm{nEq} /$ liter $(\mathrm{pH} 7.51$ ) in response to ethacrynic acid, and rose to $32.9 \mathrm{nEq} /$ liter $(\mathrm{pH} 7.48)$ after the infusion. Mean arterial carbon dioxide tension rose from a control level of 33.4 to $41.3 \mathrm{~mm} \mathrm{Hg}$ by the infusion day (before anesthesia), and fell to $33.2 \mathrm{~mm} \mathrm{Hg}$ by the morning after the infusion. ${ }^{2}$

\section{Balance Observations}

Sodium, chloride, and potassium balance data are presented in Table II for the six balance studies included in protocol I.

Alkalosis period. The administration of ethacrynic acid resulted in mean accumulated delta balances of $-80 \mathrm{mEq}$ for sodium, $-134 \mathrm{mEq}$ for chloride, and $-99 \mathrm{mEq}$ for potassium.

2 The animals were allowed to ventilate spontaneously during the light anesthesia required on the infusion day. In no instance did carbon dioxide tension appear to be influenced by the anesthesia itself; mean carbon dioxide tension was $40.3 \mathrm{~mm} \mathrm{Hg}$ after anesthesia but before the infusion, and $35.2 \mathrm{~mm} \mathrm{Hg}$ after infusion but before terminating anesthesia. 


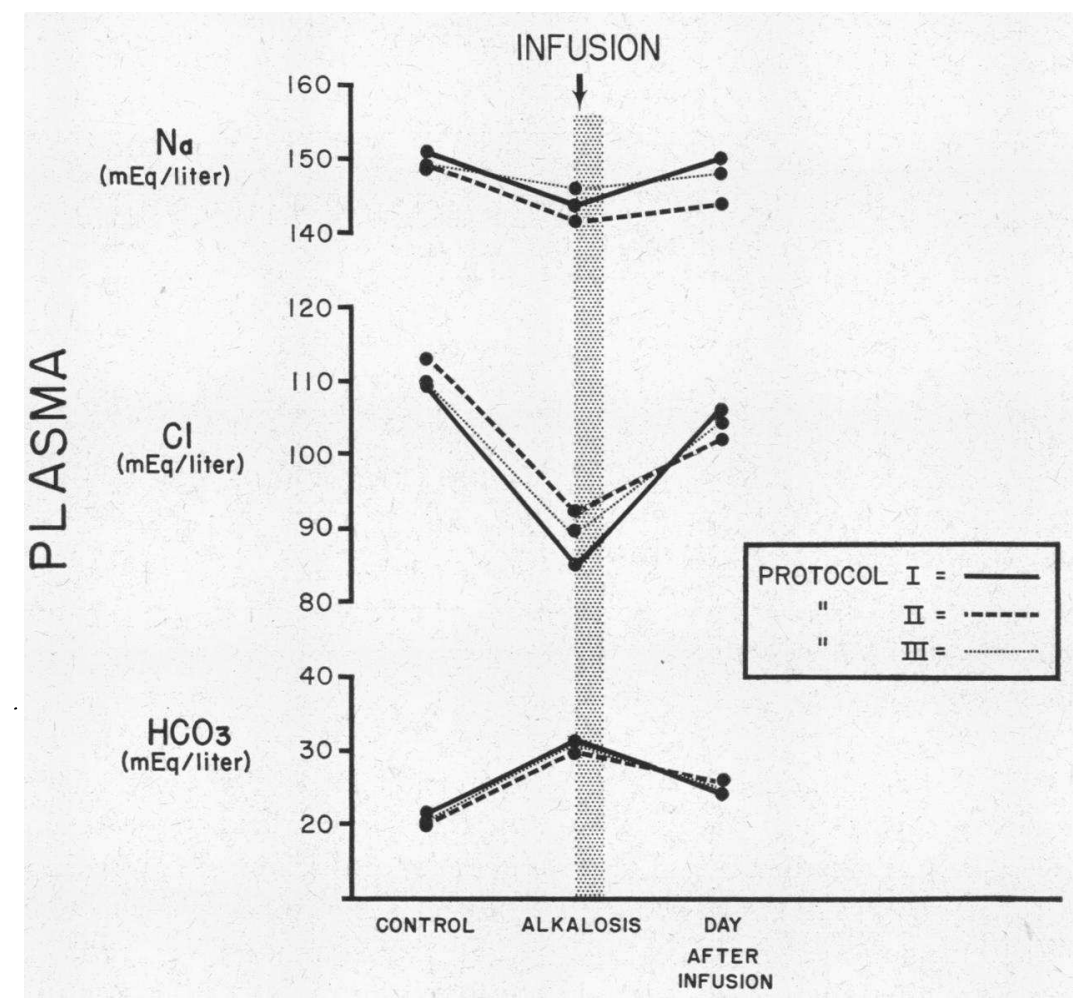

FIGURE 2 Average plasma concentrations of sodium, chloride, and bicarbonate during the control period, at the height of metabolic alkalosis, and on the morning after the infusion. Note that comparable degrees of hypochloremia and metabolic alkalosis were achieved in each protocol before infusion and that comparable degrees of repair were achieved after expansion with the standard infusion (protocol I), low chloride infusion (protocol II), and standard infusion plus deoxycortiosterone acetate (protocol III).

TABLE I

Plasma Electrolyte Concentrations for Protocol I, Standard Infusion

\begin{tabular}{|c|c|c|c|c|c|c|c|c|c|c|c|c|}
\hline \multirow[b]{2}{*}{ Dog No. } & \multicolumn{3}{|c|}{ Sodium } & \multicolumn{3}{|c|}{ Chloride } & \multicolumn{3}{|c|}{ Bicarbonate } & \multicolumn{3}{|c|}{ Undetermined anions } \\
\hline & Control & $\begin{array}{l}\text { Alka- } \\
\text { losis }\end{array}$ & $\begin{array}{c}\text { After } \\
\text { infusion } \\
\text { day }\end{array}$ & Control & $\begin{array}{l}\text { Alka- } \\
\text { losis }\end{array}$ & $\begin{array}{c}\text { After } \\
\text { infusion } \\
\text { day }\end{array}$ & Control & $\begin{array}{c}\text { Alka- } \\
\text { losis }\end{array}$ & $\begin{array}{c}\text { After } \\
\text { infusion } \\
\text { day }\end{array}$ & Control & $\begin{array}{l}\text { Alka- } \\
\text { losis }\end{array}$ & $\begin{array}{c}\text { After } \\
\text { infusion } \\
\text { day }\end{array}$ \\
\hline & \multicolumn{3}{|c|}{$m E q / l i t e r$} & \multicolumn{3}{|c|}{$m E q /$ liter } & \multicolumn{3}{|c|}{$m E q /$ liter } & \multicolumn{3}{|c|}{$m E q /$ liter } \\
\hline 1 & 154 & 146 & 151 & 110 & 88 & 107 & 22.7 & 33.3 & 21.4 & 21 & 25 & 23 \\
\hline 3 & 151 & 140 & 147 & 107 & 87 & 99 & 20.8 & 28.2 & 26.7 & 23 & 25 & 21 \\
\hline 4 & 149 & 147 & 152 & 107 & 83 & 109 & 22.8 & 32.8 & 28.6 & 19 & 31 & 14 \\
\hline 5 & 150 & 151 & 154 & 110 & 88 & 106 & 21.3 & 32.5 & 23.7 & 19 & 31 & 24 \\
\hline 6 & 150 & 141 & 146 & 108 & 86 & 102 & 20.5 & 27.6 & 22.5 & 22 & 27 & 22 \\
\hline 7 & 152 & 149 & 153 & 111 & 93 & 112 & 21.6 & 32.3 & 21.1 & 19 & 24 & 20 . \\
\hline 8 & 152 & 138 & 140 & 113 & 80 & 95 & 19.3 & 29.9 & 23.3 & 20 & 28 & 22 \\
\hline 18 & 149 & 142 & 159 & 109 & 79 & 119 & 25.1 & 34.3 & 25.8 & 15 & 29 & 14 \\
\hline Average & 151 & 144 & 150 & 109 & 86 & 106 & 21.8 & 31.4 & 24.1 & 20 & 28 & 20 \\
\hline SD & 1.6 & 4.4 & 5.4 & 1.9 & 4.3 & 7.1 & 1.7 & 2.3 & 2.5 & 2.3 & 2.5 & 3.6 \\
\hline
\end{tabular}


TABLE II

Balance Data for Protocol I, Standard Infusion

\begin{tabular}{|c|c|c|c|c|c|c|c|c|c|}
\hline \multirow[b]{2}{*}{ Dog No. } & \multicolumn{3}{|c|}{ Sodium balance } & \multicolumn{3}{|c|}{ Chloride balance } & \multicolumn{3}{|c|}{ Potassium balance } \\
\hline & $\begin{array}{l}\text { Alkalosis } \\
\text { period* }\end{array}$ & $\begin{array}{c}\text { Infusion } \\
\text { day } \ddagger\end{array}$ & Over-all & $\begin{array}{c}\text { Alkalosis } \\
\text { period }\end{array}$ & $\begin{array}{c}\text { Infusion } \\
\text { day }\end{array}$ & Over-all & $\begin{array}{l}\text { Alkalosis } \\
\text { period }\end{array}$ & $\begin{array}{c}\text { Infusion } \\
\text { day }\end{array}$ & Over-all \\
\hline & & $m E q$ & & & $m E q$ & & & $m E q$ & \\
\hline 1 & -75 & +99 & +24 & -117 & +171 & +54 & -109 & -24 & -133 \\
\hline 3 & -107 & +83 & -24 & -78 & +71 & -7 & -46 & -27 & -73 \\
\hline 5 & -172 & +120 & -52 & -192 & +164 & -28 & -226 & -28 & -254 \\
\hline 7 & -56 & +77 & +21 & -119 & +148 & +29 & -56 & -19 & -75 \\
\hline 8 & -18 & +83 & +65 & -115 & +98 & -17 & -96 & -12 & -108 \\
\hline 18 & -52 & +137 & +85 & -180 & +164 & -16 & -61 & -28 & -89 \\
\hline Average & -80 & +100 & +20 & -134 & +136 & +2 & -99 & -23 & -122 \\
\hline
\end{tabular}

* Accumulated change in net external balance before infusion.

$\ddagger$ External balance on this day only.

Consistent weight loss was observed during the alkalosis period and averaged $0.8 \mathrm{~kg}$ (range 0.4 $1.3 \mathrm{~kg}$ ). "Chloride space" calculations for the six animals on whom balance observations were available indicated a mean change in extracellular fluid volume of -0.5 liter (range -0.3 to -1.0 liter).

Infusion day period. The total amount of sodium, chloride, and bicarbonate administered on the infusion day and the accumulated urinary excretions of sodium, chloride, and net alkali are shown in the upper portion of Table III for all eight animals undergoing protocol I. An average of $319 \mathrm{mEq}$ of sodium was infused and $218 \mathrm{mEq}$ excreted. For chloride an average of $190 \mathrm{mEq}$ was

TABLE III

A Comparison of Infusion Day Data from Protocols I and IV

\begin{tabular}{|c|c|c|c|c|c|c|c|c|}
\hline \multirow[b]{2}{*}{ Dog No. } & \multicolumn{3}{|c|}{ Sodium } & \multicolumn{3}{|c|}{ Chloride } & \multicolumn{2}{|c|}{ Bicarbonate } \\
\hline & Infused & $\begin{array}{c}\text { Ex- } \\
\text { creted }\end{array}$ & $\begin{array}{c}\text { Re- } \\
\text { tained }\end{array}$ & Inf used & $\underset{\text { creted }}{\text { Ex- }}$ & $\begin{array}{c}\text { Re- } \\
\text { tained }\end{array}$ & Infused & $\begin{array}{c}\text { F.x- } \\
\text { creted* }\end{array}$ \\
\hline & \multicolumn{3}{|c|}{$m E q$} & \multicolumn{3}{|c|}{$m E q$} & \multicolumn{2}{|c|}{$m E q$} \\
\hline Protocol I & & & & & & & & \\
\hline 1 & 346 & 247 & 99 & 220 & 49 & 171 & 82 & 98 \\
\hline 3 & 260 & 177 & 83 & 148 & 77 & 71 & 59 & 11 \\
\hline 4 & 269 & 147 & 122 & 153 & 18 & 135 & 69 & 34 \\
\hline 5 & 418 & 298 & 120 & 248 & 84 & 164 & 88 & 75 \\
\hline 6 & 289 & 201 & 88 & 181 & 49 & 132 & 67 & 65 \\
\hline 7 & 320 & 243 & 77 & 196 & 48 & 148 & 67 & 84 \\
\hline 8 & 243 & 160 & 83 & 139 & 41 & 98 & 57 & 23 \\
\hline 18 & 407 & 270 & 137 & 236 & 72 & 164 & 110 & 73 \\
\hline Average & 319 & 218 & 101 & 190 & 55 & 135 & 75 & 58 \\
\hline \multicolumn{9}{|c|}{ Protocol IV } \\
\hline 11 & 369 & 326 & 43 & 278 & 226 & 52 & 48 & 11 \\
\hline $1 \mathrm{~B}$ & 359 & 262 & 97 & 260 & 151 & 109 & 59 & 29 \\
\hline $5 \mathrm{~B}$ & 472 & 337 & 135 & 366 & 226 & 140 & 60 & 9 \\
\hline 20 & 423 & 269 & 154 & 276 & 120 & 156 & 52 & 36 \\
\hline 24 & 306 & 198 & 108 & 215 & 120 & 95 & 44 & 3 \\
\hline Average & 385 & 278 & 107 & 279 & 169 & 110 & 53 & 18 \\
\hline
\end{tabular}

*Values shown are for net alkali excretion (urinary bicarbonate-urinary ammonium-titratable acidity). 


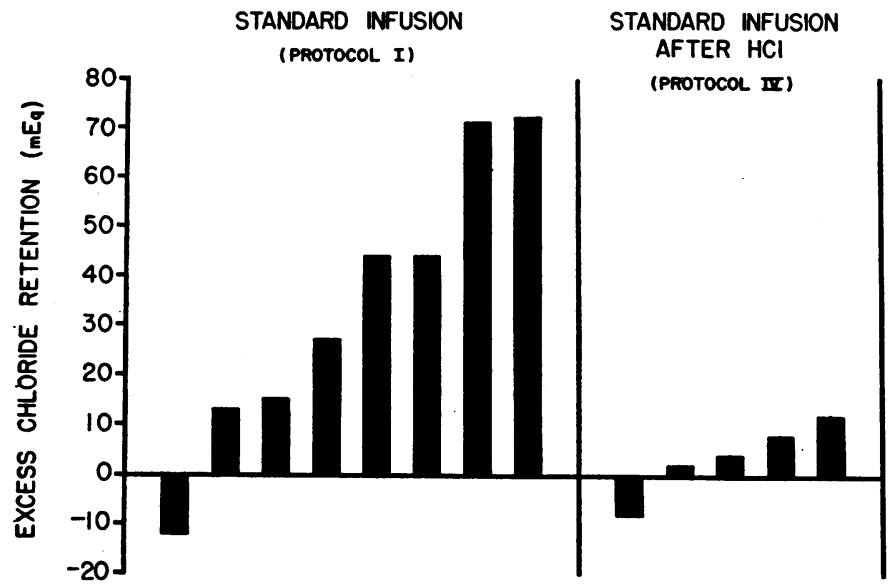

Figure 3 Chloride retention in excess of sodium retention on the infusion day for each animal in protocol I and protocol IV. Each bar represents the difference between the infusion day chloride balance and the infusion day sodium balance. Chloride was retained in significant excess of sodium in response to isometric expansion in protocol I when metabolic alkalosis was present but not in response to comparable expansion in protocol IV after metabolic alkalosis had been corrected with hydrochloric acid.

infused but only $55 \mathrm{mEq}$ excreted. As a result, previously accumulated sodium and chloride deficits, determined in the six balance studies (Table II), were repaid; on the morning after infusion over-all accumulated balance averaged $+20 \mathrm{mEq}$ for sodium and $+2 \mathrm{mEq}$ for chloride. The differences between the infusion day balances for chloride and those for sodium for all eight animals undergoing protocol I are illustrated in the lefthand panel of Fig. 3; an average of $34 \mathrm{mEq}$ of chloride was retained in excess of sodium for this group $(P<0.02)$.

Table III also relates the amount of bicarbonate infused to the accumulated net alkali excreted for the $24 \mathrm{hr}$ period after the infusion. An average of $75 \mathrm{mEq}$ of bicarbonate was infused and $58 \mathrm{mEq}$ of net alkali was excreted. ${ }^{3}$

Infusion of the potassium-free solution was followed by additional losses of potassium on the infusion day which averaged $23 \mathrm{mEq}$ and which resulted in a mean accumulated deficit over the entire study of $-122 \mathrm{mEq}$.

Mean body weight at the end of the infusion day was not significantly different from that just before

3 Daily net acid excretion during the initial control period averaged $65 \mathrm{mEq}$ for the six balance animals. This figure, however, cannot be used with confidence as a base line to assess the net suppression of acid excretion on the infusion day since endogenous acid production was probably altered during this day by such events as anesthesia and fasting.

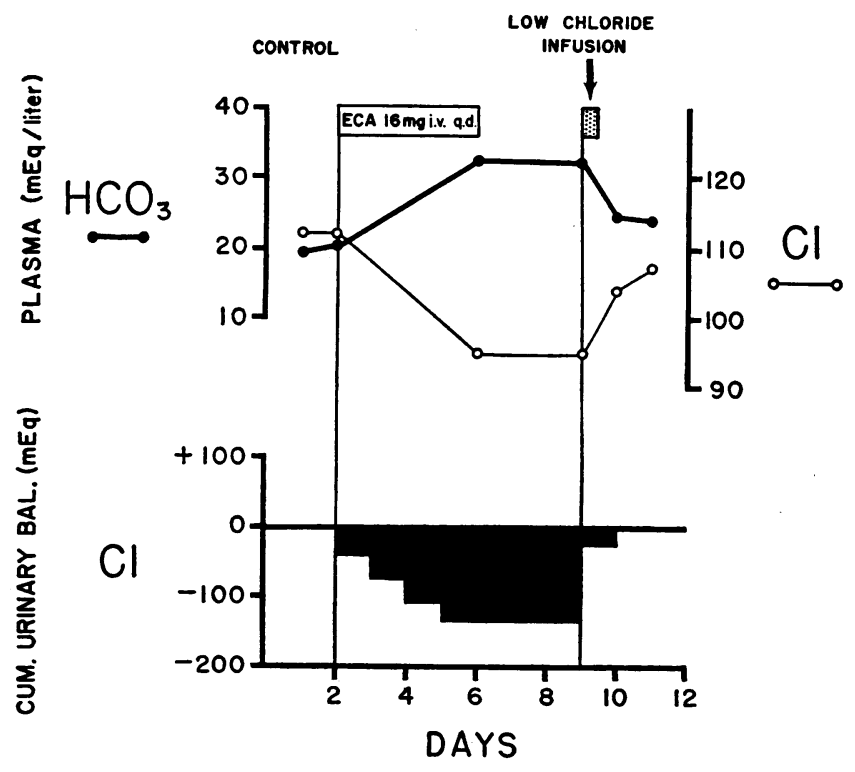

FIGURE 4 Plasma concentration of bicarbonate and chloride and cumulative (CUM.) urinary balance ( $B A L$.$) of chloride during the time course of one$ representative study from protocol II. (dog 14). Note that plasma chloride concentration rose and chloride deficits were largely repaid in response to the hypochloric infusion. 
infusion. Extracellular fluid volume, on the other hand, as estimated from "chloride space" calculations, exhibited a consistent increase which averaged 0.6 liter. Shifts of sodium and potassium between intra- and extracellular compartments were computed from "chloride space" estimates and plasma concentrations. Whereas sodium did not appear to shift consistently in either direction, potassium did appear to shift out of cells in all studies, the mean shift of potassium amounting to $25 \mathrm{mEq}$. As a consequence, an average of $27 \mathrm{mEq}$ of hydrogen ions appeared to shift into cells during the infusion day.

\section{Protocols II and III}

Pertinent plasma values and urinary chloride balances are depicted in Fig. 4 for one representative study ( $\operatorname{dog} 14$ ) from protocol II.

Fig. 2 illustrates the average plasma sodium, chloride, and bicarbonate concentrations for the three animals undergoing protocol II (dashed line) and for the three animals undergoing protocol III (dotted line) for each of the experimental periods. In each of these protocols the changes observed in the plasma concentration of major electrolytes were comparable to those observed in protocol I; chloride concentration rose and bicarbonate concentration fell towards control levels in response to the individually tailored infusion despite the administration of a solution with only one-half the chloride concentration of the animal's plasma (protocol II) or the presence of excessive mineralocorticoid (protocol III).

Accumulated urinary chloride losses in response to ethacrynic acid administration averaged 136 $\mathrm{mEq}$ (range 124-149 $\mathrm{mEq}$ ) for protocol II and $143 \mathrm{mEq}$ (range 113-198 $\mathrm{mEq}$ ) for protocol III. These chloride deficits were similar to those observed in protocol I (Table II) and were equally well repaid on the infusion day; chloride retention from the individually tailored solutions averaged $112 \mathrm{mEq}$ (range 107-119 $\mathrm{mEq}$ ) for protocol II and $156 \mathrm{mEq}$ (range 126-196 $\mathrm{mEq}$ ) for protocol III).

\section{Protocol IV}

Pertinent observations for one representative study $(\operatorname{dog} 5 \mathrm{~B})$ are shown in Fig. 5.

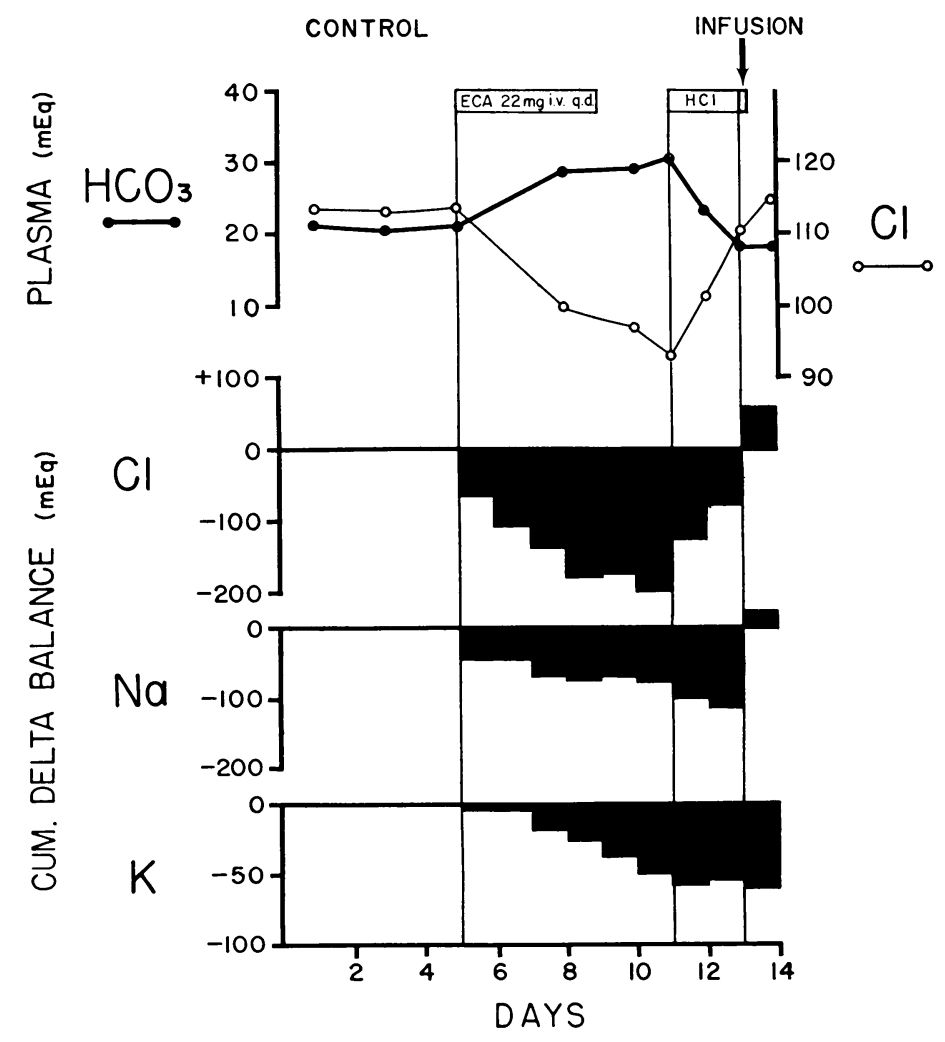

Figure 5 Plasma concentrations of bicarbonate and chloride and cumulative delta balances of chloride, sodium, and potassium during the time course of one representative study from protocol IV. ( $\operatorname{dog} 5 \mathrm{~B})$. Note that metabolic alkalosis and much of the chloride deficit had been repaired by hydrochloric acid before isometric expansion with the individually tailored infusion. The infusion resulted in complete repair of sodium deficits without appreciable further alteration in plasma anion concentrations. 


\section{Plasma Values}

Table IV contains the values for all five animals undergoing protocol IV. Control values represent the mean of the three to four observations obtained before the administration of ethacrynic acid. "Alkalosis" values were obtained immediately before giving the first dose of hydrochloric acid and represent the extreme of metabolic alkalosis in each animal. Values labeled "after $\mathrm{HCl}$ " represent the average of the two to four observations obtained in the 1 st or $2 \mathrm{nd} \mathrm{hr}$ immediately before the infusion; values labeled "after infusion day" were obtained $24 \mathrm{hr}$ later.

As can be seen from a comparison of Tables I and IV, mean plasma electrolyte concentrations during the control period and after the administration of ethacrynic acid were quite similar for the groups of animals undergoing protocols I and IV. In protocol IV, however, the plasma anion concentrations characteristic of the alkalosis period were returned virtually to normal by the adminis- tration of hydrochloric acid and, despite the subsequent infusion, did not change appreciably thereafter.

\section{Balance Observations .}

Alkalosis period. The changes in net external balance, accumulated before the infusion day, averaged $-101 \mathrm{mEq}$ for sodium (range -63 to -171 $\mathrm{mEq}$ ) and $-88 \mathrm{mEq}$ for potassium (range -76 to $-118 \mathrm{mEq}$ ). The change in net chloride balance, accumulated during the development of metabolic alkalosis and before the administration of hydrochloric acid, averaged $-145 \mathrm{mEq}$ (range -104 to $-200 \mathrm{mEq}$ ). Each of these mean values is comparable to that observed during the alkalosis period in protocol I (Table II). Administration of hydrochloric acid reduced the mean accumulated net chloride deficits to $-56 \mathrm{mEq}$ (range -18 to -79 $\mathrm{mEq}$ ) before the infusion day.

Infusion day period. The total amount of sodium, chloride, and bicarbonate administered on

TABLE IV

Plasma Electrolyte Concentrations for Protocol IV, Standard Infusion after Correction of Metabolic Alkalosis with $\mathrm{HCl}$

\begin{tabular}{|c|c|c|c|c|c|c|c|c|c|c|}
\hline \multirow[b]{2}{*}{ Dog No. } & \multicolumn{5}{|c|}{ Sodium } & & \multicolumn{4}{|c|}{ Chloride } \\
\hline & & Control & Alkalosis & $\begin{array}{c}\text { After } \\
\mathrm{HCl}\end{array}$ & $\begin{array}{c}\text { After } \\
\text { infusion } \\
\text { day }\end{array}$ & & Control & Alkalosis & $\begin{array}{c}\text { After } \\
\mathrm{HCl}\end{array}$ & $\begin{array}{c}\text { After } \\
\text { infusion } \\
\text { day }\end{array}$ \\
\hline \multicolumn{7}{|c|}{$m E q / l i t e r$} & \multicolumn{4}{|c|}{$m E q /$ liter } \\
\hline $1 \mathrm{~B}$ & & 160 & 154 & 154 & 154 & & 112 & 92 & 104 & 113 \\
\hline $5 \mathrm{~B}$ & & 158 & 156 & 154 & 158 & & 113 & 93 & 110 & 115 \\
\hline 11 & & 150 & 151 & 147 & 150 & & 114 & 101 & 111 & 116 \\
\hline 20 & & 149 & 151 & 149 & 155 & & 110 & 91 & 104 & 112 \\
\hline 24 & & 156 & 146 & 143 & 145 & & 104 & 77 & 104 & 114 \\
\hline Average & & 155 & 152 & 149 & 152 & & 111 & 91 & 107 & 114 \\
\hline SD & & 4.4 & 3.4 & 4.2 & 4.5 & & 3.6 & 7.8 & 3.2 & 1.4 \\
\hline \multicolumn{5}{|c|}{ Bicarbonate } & & \multicolumn{5}{|c|}{ Undetermined anions } \\
\hline Control & Alkalosis & & $\begin{array}{c}\text { After } \\
\mathrm{HCl}\end{array}$ & $\begin{array}{c}\text { After } \\
\text { infusion } \\
\text { day }\end{array}$ & & Control & Alkalosis & & $\begin{array}{c}\text { After } \\
\mathrm{HCl}\end{array}$ & $\begin{array}{c}\text { After } \\
\text { infusion } \\
\text { day }\end{array}$ \\
\hline \multicolumn{5}{|c|}{$m E q /$ liter } & & \multicolumn{5}{|c|}{$m E q / l i t e r$} \\
\hline 23.4 & 32.8 & & 23.0 & 22.4 & & 25 & 29 & & 27 & 19 \\
\hline 21.0 & 30.4 & & 17.8 & 17.9 & & 24 & 33 & & 26 & 25 \\
\hline 22.1 & 31.0 & & 16.8 & 17.8 & & 14 & 19 & & 19 & 16 \\
\hline 20.3 & 32.3 & & 18.5 & 15.8 & & 19 & 28 & & 27 & 27 \\
\hline 19.5 & 30.8 & & 20.3 & 19.3 & & 33 & 38 & & 19 & 12 \\
\hline 21.3 & 31.5 & & 19.1 & 18.6 & & 23 & 29 & & 24 & 20 \\
\hline 1.4 & 0.9 & & 2.2 & 2.2 & & 6.4 & 6.3 & & 3.8 & 5.6 \\
\hline
\end{tabular}


the infusion day and the accumulated urinary excretion of sodium, chloride, and net alkali are shown in the lower portion of Table III for each of the five animals undergoing protocol IV. For sodium, an average of $385 \mathrm{mEq}$ was infused and $278 \mathrm{mEq}$ excreted; $107 \mathrm{mEq}$ was retained, a value remarkably similar to that observed in protocol I. For chloride, however, an average of $279 \mathrm{mEq}$ was infused and $169 \mathrm{mEq}$ excreted ; only $110 \mathrm{mEq}$ was retained. As seen in the right-hand panel of Fig. 3, chloride was not retained in significant excess of simultaneous sodium retention, as was the case in protocol I, even though relatively more chloride was administered than in protocol I. From the standpoint of urinary composition, chloride excretion averaged $60 \%$ of sodium excretion on the infusion day of protocol IV whereas chloride excretion averaged only $25 \%$ of sodium excretion on the infusion day of protocol I.

\section{DISCUSSION}

The relationship between metabolic alkalosis and the metabolism of chloride has been the subject of considerable investigation in recent years (1-8). It has been well established by these studies that selective depletion of body chloride stores results in metabolic alkalosis, restricted access to dietary chloride permits metabolic alkalosis to perpetuate itself and provision of chloride is a prerequisite to the repair of metabolic alkalosis.

The self perpetuation of metabolic alkalosis during the period of chloride deficiency has been tentatively attributed to an alteration in renal tubular function necessitated by the accompanying hypochloremia (6). Since chloride is virtually the only physiologically prevalent anion that can readily penetrate the tubular epithelium, it has been reasoned that a low concentration of chloride in the glomerular filtrate places a limit on the amount of anion available for reabsorption with sodium. As a result of this limitation, conservation of filtered sodium would require an acceleration of sodium-cation exchange (12). To the extent that sodium-hydrogen exchange were thus accelerated, a sustained increase in bicarbonate reabsorption would result and metabolic alkalosis would be perpetuated.

If hypochloremia necessitates an accelerated sodium-hydrogen exchange during selective chlo- ride depletion, an increase in chloride concentration towards normal might be the necessary first step that permits a decelerated sodium-hydrogen exchange during chloride repletion.

The present study explores this thesis by isolating filtrate chloride concentration as a variable during the replacement of chloride deficits in metabolic alkalosis and by observing the kidney's ability to return plasma composition to normal. Dogs were rendered chloride depleted, hypochloremic, and alkalotic by the administration of ethacrynic acid and a chloride-deficient diet. At the height of the metabolic alkalosis the dogs received an infusion designed to provide abundant chloride isometrically, i.e., without altering the plasma concentration of major electrolytes (protocol I). Consequently, the composition of glomerular filtrate, and the profile of potentially reabsorbable substrate presented to the tubule were unchanged by the infusion itself. If the concentration of chloride in the filtrate were a critical determinant of the rate of cation exchange, deceleration of sodium-hydrogen exchange and a fall in bicarbonate threshold might not have been expected to occur under these conditions.

The results of protocol I indicate, however, that the renal tubules were able to effect appropriate adjustments of extracellular composition in response to such infusions; the bulk of the infused sodium was rejected while the infused chloride was selectively retained, net acid excretion was promptly suppressed and, consequently, over the ensuing $24 \mathrm{hr}$, plasma chloride and bicarbonate concentrations were returned essentially to normal levels. Moreover, the results of protocol II demonstrate that, even when a low filtrate chloride concentration is reduced further by the direct effects of infusing a solution with a substantially lower chloride concentration, the kidneys are still able to retain requisite chloride selectively and readjust plasma composition towards normal. It is evident, therefore, that a low filtrate chloride concentration does not necessitate an accelerated rate of bicarbonae reabsorption under all circumstances.

While clearly not invalidating the notion that, before administering exogenous chloride, hypochloremia may be a crucial factor in the mechanisms perpetuating alkalosis, the present observations do suggest that mechanisms independent of filtrate chloride concentration may operate to cor- 
rect metabolic alkalosis once provision of needed chloride has occurred.

The theoretical mechanisms enumerated below, each initiated by acute expansion of extracellular fluid volume, could account for the observed correction of metabolic alkalosis since each would permit infused sodium to be excreted without a proportionate excretion of chloride.

(a) An increase in glomerular filtration rate, in response to volume expansion could have resulted in the observed alkali diuresis and selective retention of chloride even if sodium-hydrogen exchange continued at an undiminished rate. This possibility would require that such infusions promote sustained increases in the rate of both glomerular filtration and over-all sodium reabsorption so that only the relative rate of sodium-hydrogen exchange was reduced. Direct evidence bearing on this point is not available from the present study since filtration rates were not measured. There would appear to be no reason to doubt, however, that such brisk infusions produced at least transient increases in the rate of glomerular filtration in these previously sodium depleted animals. Further study will be required to clarify this important point.

(b) Volume expansion could have resulted in a selective suppression of sodium-hydrogen exchange by inhibiting endogenous mineralocorticoid production. Since aldosterone is thought to promote sodium-cation exchange, diminished aldosterone activity as a consequence of volume expansion could have dampened this exchange and resulted in what appeared to be "selective" chloride retention. The results of protocol III, however, do not support this contention since pharmacological amounts of the mineralocorticoid, DOCA, did not prevent the alkali diuresis, the preferential retention of chloride, and the restoration of plasma composition towards normal.

(c) Expansion of extracellular fluid volume could have resulted in selective inhibition of sodium-hydrogen exchange by the renal tubule through some mechanism other than suppressed mineralocorticoid production. It is well recognized that volume expansion may inhibit sodium reabsorption independent of changes in mineralocorticoid levels (13-15). It is conceivable that such inhibition of sodium reabsorption involves inhibition of sodium-bicarbonate reabsorption to a proportionately greater extent than it does sodium- chloride reabsorption. However, it seems clear from the results of protocol IV that mere expansion of volume, at least with solutions such as those employed here, does not invariably produce a disproportionate inhibition of bicarbonate reabsorption. In these studies, similarly volumedepleted animals were acutely expanded with comparable solutions after previous restoration of nearly normal plasma anion concentrations. The saluresis observed after volume repair which occurred under these circumstances was accompanied by a proportionate chloruresis; by contrast, in protocol I a similar saluresis was accompanied by very little chloruresis. Viewed conversely, despite the retention of similar amounts of sodium, excess chloride was retained only in protocol $I$ when appreciable chloride deficits were present and not in protocol IV when chloride deficits had been largely repaid. It seems clear from these observations that the anion composition of extracellular fluid must be an important determinant of the urinary composition that results from isometric expansion of extracellular volume. The mechanism enabling the renal tubule to make the appropriate adjustments in urinary composition under these conditions is still unclear.

(d) A fourth consequence of volume expansion would appear to offer the most plausible explanation for these results. It is not unreasonable to postulate that, before volume expansion, the rate of sodium reabsorption in the proximal tubule was increased in response to the previously accumulated sodium deficits and that the delivery of filtrate to the distal nephron was decreased accordingly. Once the infusion solution was administered and extracellular fluid volume restored, the rate of sodium reabsorption in the proximal tubule was probably diminished (16). As a direct consequence of this decrease in proximal sodium reabsorption, filtered chloride as well as sodium might have been shunted to more distal sites in the nephron providing these sites with a greatly increased opportunity to modify the tubular urine. If such distal sites possessed a mechanism for selective or preferential chloride reabsorption under conditions of chloride depletion or hypochloremia, the results of the present study would be explained.

Despite the emphasis in the foregoing discussion on the role played by volume expansion in accounting for the present results, it should not be 
assumed that volume expansion without chloride might have produced the same results. The administration of sodium without the provision of exogenous chloride (or equivalent reabsorbable anion) could not have resulted in correction of metabolic alkalosis since, in the absence of a decrease in plasma sodium concentration or an increase in undetermined anion concentration, a fall in plasma bicarbonate concentration necessitates at least a reciprocal increase in chloride concentration as a direct consequence of the constraints of electroneutrality. Furthermore, the present study strongly suggests not only that the repair of metabolic alkalosis is dependent on the provision of chloride but also that the repair of volume deficits by the retention of administered sodium is also dependent on the availability of this anion. During the several days between the last dose of ethacrynic acid and the infusion day, ample sodium, $3 \mathrm{mEq} /$ $\mathrm{kg}$ per day, was present in the chloride-deficient diet of these animals but sodium deficits were not repaid. It was not until the infusion day when chloride was also made available that sodium retention occurred and normovolemia restored.

It would appear that the repair of metabolic alkalosis by the kidneys under the conditions of the present study is the result of a process in which the repair of volume deficits and the provision of chloride are inseparable and interdependent features.

\section{REFERENCES}

1. Schwartz, W. B., R. M. Hays, A. Polak, and G. D. Haynie. 1961. Effects of chronic hypercapnia on electrolyte and acid-base equilibrium. II. Recovery with special reference to the influence of chloride intake. J. Clin. Invest. 40: 1238.

2. Atkins, E. L., and W. B. Schwartz. 1962 Factors governing correction of the alkalosis associated with potassium deficiency; the critical role of chloride in the recovery process. J. Clin. Invest. 41: 218.

3. Gulyassy, P. F., C. van Ypersele de Strihou, and
W. B. Schwartz. 1962. On the mechanism of nitrateinduced alkalosis. The possible role of selective chloride depletion in acid-base regulation. J. Clin. Invest. 41: 1850.

4. DeGraeff, J., A. Struyvenberg, and L. D. F. Lameijer. 1964. The role of chloride in hypokalemic alkalosis. Am. J. Med. 37: 778.

5. Needle, M. A., G. J. Kaloyanides, and W. B. Schwartz. 1964. The effects of selective depletion of hydrochloric acid on acid-base and electrolyte equilibrium. J. Clin. Invest. 43: 1836.

6. Kassirer, J. P., P. M. Berkman, D P. Lawrenz, and W. B. Schwartz. 1965. The critical role of chloride in the correction of hypokalemic alkalosis in man Am. J. Med. 38: 172.

7. Kassirer, J. P., and W. B. Schwartz. 1966. The response of normal man to selective depletion of hydrochloric acid. Am. J. Med. 40: 10.

8. Kassirer, J. P., and W. B. Schwartz. 1966. Correction of metabolic alkalosis in man without repair of potassium deficiency. Am. J. Med. 40: 19.

9. Cotlove, E., and H. H. Nishi. 1961. Automatic titrations with direct read-out of chloride concentration. Clin. Chem. 7: 285.

10. Fiske, C. H., and Y. Subbarow. 1925. The colorimetric determination of phosphorus. J. Biol. Chem. 66: 375.

11. Logsdon, E. E. 1960. A method for the determination of ammonia in biologic materials on the autoanalyzer. Ann. N. Y. Acad. Sci. 87: 801.

12. Bank, N., and W. B. Schwartz. 1960. The influence of anion penetrating ability on urinary acidification and the excretion of titratable acid. J. Clin. Invest. 39: 1516.

13. DeWardener, H. E., I. H. Mills, W. F. Clapham, and C. J. Hayter. 1961. Studies on the efferent mechanism of the sodium diuresis which follows the administration of intravenous saline in the dog. Clin. Sci. 21: 249.

14. Mills, I. H., H. E. DeWardener, C. J. Hayter, and W. F. Clapham. 1961. Studies on the afferent mechanism of the sodium chloride diuresis which follows intravenous saline in the dog. Clin. Sci. 21: 259.

15. Levinsky, N. G., and R. C. Lalone. 1963. The mechanism of sodium diuresis after saline infusion in the dog. J. Clin. Invest. 42: 1261.

16. Dirks, J. H., W. J. Cirksena, and R. W Berliner. 1965. The effect of saline infusion on sodium reabsorption by the proximal tubule of the dog. J. Clin. Invest. 44: 1160 . 